\title{
Oncogene Activation Process
}

National Cancer Institute

\section{Source}

National Cancer Institute. Oncogene Activation Process. NCI Thesaurus. Code C18909.

Any DNA sequence alteration process occurring in a proto-oncogene, resulting in loss of regulation of the gene product, and predisposing the cell to neoplastic transformation. Proto-oncogenes are ordinarilly involved in transduction of signals that regulate cell growth and differentiation. Activation of such genes overrides the normal mechanisms of regulation and is an important step in the process of cellular transformation. 